\title{
REFERENCIAS INDICATIVAS DE LOS PROCESOS DE CAMBIO TERRITORIAL EN UN ESPACIO DE MONTAÑA (SECTOR CENTRAL DE LA MONTAÑA CANTÁBRICA) *
}

\author{
Carmen Delgado Viñas ${ }^{(*)}$, Carmen Gil de Arriba ${ }^{(*)}$, Luis-Alfonso \\ Hortelano Mínguez $^{(* *)}$ y Juan Ignacio Plaza Gutiérrez ${ }^{(* * *)}$ \\ (*) Departamento de Geografía, Urbanismo y Ordenación del Territorio. \\ Universidad de Cantabria. \\ (**) Departamento de Geografía. Universidad de Salamanca. \\ $\left(^{\star * *}\right)$ Departamento de Geografía, Urbanismo y Ordenación del Territorio. \\ Universidad de Salamanca
}

\begin{abstract}
Resumen: Esta contribución quiere reflexionar sobre los procesos de transformación territorial que se han desarrollado en el último decenio del siglo $\mathrm{XX}$ sobre un espacio de montaña (sector central de la Cordillera Cantábrica: Montaña Palentina y Sur de Cantabria). Se centra en el propio territorio como objeto principal de análisis a partir de la formulación de algunas proposiciones previas que orientan esta aportación: cambios en la gestión del territorio; cambios en la propia imagen de estos espacios de montaña; cambios en la conceptualización y "funcionalidad" asignados a este espacio dentro de los nuevos modelos y propuestas de ordenación y desarrollo territorial; y cambios, asimismo, en las formas y estructuras de organización territorial interna. Para desarrollar estas orientaciones generales se analizarán, en primer lugar, los factores más notables que han provocado las transformaciones apuntadas y, a continuación, se procederá a destacar las principales direcciones y manifestaciones de los cambios producidos.
\end{abstract}

Palabras clave: turismo rural; terciarización; estructuración territorial; paisajes protegidos, montaña cantábrica.

\begin{abstract}
This contribution wants to meditate on the processes of territorial transformation that have been developed in the last decade of the XX century on a mountain space (central sector of the Cantabrian Mountain range: Mountain Palentina and South of Cantabria). Study the own territory as main object of analysis starting from the formulation of some previous propositions that they
\end{abstract}

* Recibido: 10-11-03. Aceptado: 04-06-04. 
guide this contribution: changes in the administration of the territory; changes in the own image of these mountain spaces; changes in the conceptualization and "functionality " assigned to this space inside the new models and ordination proposals and territorial development; and changes, also, in the forms and structures of internal territorial organization. To develop these general orientations they will be analyzed, in the first place, the most remarkable factors that have caused the pointed transformations and, next, you will proceed to highlight the main addresses and manifestations of the produced changes.

Key words: rural tourism; third sector increase; territorial structuring; protected landscapes, cantabrica mountain.

\section{Introducción}

El presente trabajo, que da continuidad al programa de difusión de resultados de los proyectos de investigación en que se apoya (Plan I+D+I 2000-2003 del Ministerio de Educación y Cultura y Programa de Apoyo a Proyectos de Investigación de la Junta de Castilla y León), quiere proporcionar una apretada síntesis sobre algunas de las transformaciones territoriales más importantes (que afectan a sus bases estructurales, espaciales, paisajísticas, etc.) experimentadas por algunas comarcas montañosas del norte de España, de manera más particular las de su sector central-Montaña Palentina y Comarcas del sur de Cantabria-, abarcando, para ello, un conjunto más amplio de formas de uso y ocupación del territorio montañés -más allá del ámbito agrario- y de elementos y factores de su organización que han empezado a ser representativas de lo que puede ser un nuevo modo más diversificado de gestión, utilización y explotación socioeconómica y espacial de estas zonas en los decenios finales del siglo XX, pues realmente han introducido cambios importantes en los últimos años y, en ciertos casos, han marcado los perfiles socioeconómicos de estos espacios de montaña.

\section{Breve presentación del territorio montañés estudiado}

La Cordillera Cantábrica es una alineación que actúa como divisoria hidrográfica y administrativa entre la Meseta (Comunidad Autónoma de Castilla y León) y las regiones septentrionales que vierten directamente al Cantábrico (Asturias, Cantabria y País Vasco). En su vertiente sur se extiende por el extremo norte de las provincias castellano-leonesas de León, Palencia y Burgos. La Montaña Palentina, con una extensión cercana a los $1.800 \mathrm{~km}^{2}$, se sitúa entre el Macizo Asturiano (comarca de Guardo 
y parte de la de Cervera) y el sector oriental de la Cordillera Cantábrica (borde este de la comarca de Cervera y toda la comarca de Aguilar) y ocupa una posición geográfica central dentro de toda esta barrera montañosa del norte de España (Alario Trigueros, 2002; Plaza Gutiérrez, 1992), al igual que las comarcas montañosas que ocupan la vertiente norte y cierran por el sur la Comunidad Autónoma de Cantabria (Liébana, Cabuérniga-Tudanca y Campoo-Los Valles -ésta última conocida como comarca campurriana, cuyo centro es la ciudad de Reinosa-), con las que mantiene muchas afinidades y relaciones (todavía más frecuentes en el pasado), definiendo de este modo un conjunto específico y preciso: el sector central de la Montaña Cantábrica ${ }^{2}$.

Los principales centros rectores de este territorio son los de Reinosa, Guardo, Aguilar de Campoo, Cervera de Pisuerga y Potes, si bien son los dos primeros y en menor medida también Aguilar, los que adoptan formas y dimensiones más propias

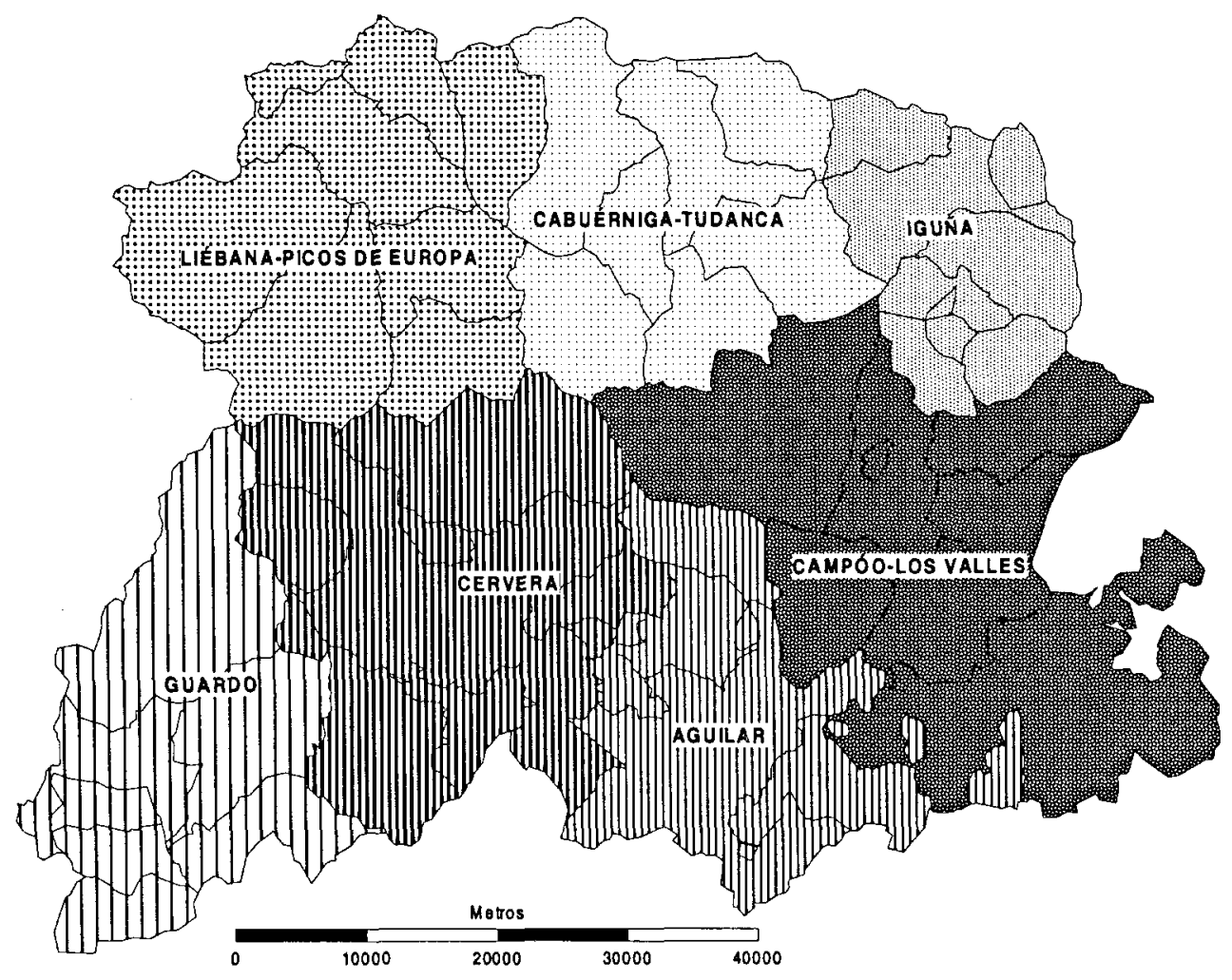

Mapa 1. Comarcas del sector central de la Montaña Cantábrica. 
de centros urbanos aunque de niveles medios y pequeños (Cuadro 1). Núcleos que, indistintamente hasta fechas muy recientes, han estado vinculados a la presencia de actividades y empresas industriales y extractivas que han marcado su especialización funcional y productiva, ya hoy profundamente reestructurada y muy reducida, pese a la persistencia de algunas más particularmente ligadas al sector agroalimentario (fabricación galletera en Aguilar de Campoo). Es, por lo demás, un espacio de montaña que se extiende por $4.251,90 \mathrm{~km}^{2}(1.784,10$ de la Montaña Palentina y $2.467,80$ del sur de Cantabria), agrupa a 492 entidades de población, 52 municipios y 7 comarcas (ver mapa 1) y en el que viven 66.882 habitantes, con una densidad media de 15,7 hab. $/ \mathrm{km}^{2}$.

Cuadro 1. Indicadores de "funcionalidad" de los principales centros urbanos del sector central de la Montaña Cantábrica.

\begin{tabular}{|lccc|}
\hline Centros & $\begin{array}{c}\text { Población (2000) } \\
\text { (1) }\end{array}$ & $\begin{array}{c}\text { Registros IAE 2000 } \\
\text { (2) }\end{array}$ & $\begin{array}{c}\text { Empresas } \\
\text { (3) }\end{array}$ \\
\hline Aguilar de Campoo & 7.643 hab. & $33,8 \%$ & 45 \\
Cervera de Pisuerga & 2.706 hab. & $12,3 \%$ & 8 \\
Guardo & 8.645 hab. & $29,4 \%$ & 16 \\
Potes & 1.573 hab. & $10,0 \%$ & 6 \\
Reinosa & 11.193 hab. & $33,3 \%$ & 46 \\
\hline
\end{tabular}

(1): Volumen tomado del Padrón Municipal de habitantes del año 2000.

(2): Porcentaje de registros de cada centro sobre el total de registros de toda la comarca respectiva (de la vertiente cántabra para el caso de Cantabria -comarcas del sur-suroeste cántabro- y de la Montaña Palentina para el caso de la vertiente castellano-leonesa o palentina -comarcas de Guardo, Cervera y Aguilar--). Tonados de los listados del Impuesto sobre Actividades Económicas (IAE) de las Cámaras de Comercio e Industria de Cantabria y de Palencia referidos al año 2000.

(3): Número de empresas de entre todas las empresas más representativas o notables recogidas en los listados que periódicamente selecciona la empresa Edicon. (Grupo Telecyl) en su. Guia Empresarial, que en el presente caso se corresponde con las ediciones 2000-2001 de Cantabria y de Castilla y León.

Sus recursos hídricos se reparten entre la cuenca norte de España (valle de la Liébana, valles del Saja y Nansa y valle del Besaya, en Cantabria, y un reducidísimo ángulo septentrional de La Pernía palentina), la cuenca del Ebro (valles cántabros meridionales de Campoo y Valderredible, incluyendo en ellos los tres enclaves palentinos allí existentes: Berzosilla, Lastrilla y Cezura) y dos cuencas tributarias del Duero, las de los ríos Carrión y Pisuerga (que drenan la práctica totalidad de la Montaña Palentina). Todo su volumen de agua se encuentra regulado por nueve embalses, cuatro en Cantabria (de los que el mayor de todos es el del Ebro, en la comarca campurriana) y cinco en la Montaña Palentina. 
Los principales recursos naturales sobre los que se han sustentado las formas de explotación socioeconómica del medio más destacadas en la Montaña Cantábrica han sido los forestales (dominio de un bosque atlántico donde hayedos y robledales son sus formaciones más importantes, sin excluir otros enclaves más mediterráneos hacia el borde sur -también en las partes bajas de la Liébana cántabra- y las masas de pinares de repoblación), los pratenses (con una profusa extensión lograda por prados naturales y pastizales de montaña, base territorial para el mantenimiento de una cabaña ganadera dominada sobre todo por el vacuno y que ha trazado el perfil más identificativo de Cantabria) y los minerales (donde el carbón, fundamentalmente la hulla pero también la antracita, ha dado lugar a la implantación y desarrollo de una actividad minera, hoy ya muy declinante, que explotó el importante paquete de materiales carboníferos de esta zona de montaña, especialmente en las cuencas carboníferas de la Montaña Palentina: Guardo-La Peña y Barruelo-Orbó-La Pernía). A ellas han de unirse, además, las actividades industriales que arraigaron, sobre todo, en Reinosa, en algunos núcleos del valle del Besaya y en los dos extremos de la Montaña Palentina (Guardo y Velilla en el oeste y Aguilar de Campoo en el este) y que han experimentado importantes reestructuraciones y cierres.

\section{Formulación de algunas proposiciones previas de análisis}

Entender la nueva funcionalidad y las orientaciones que más recientemente han adoptado estos espacios rurales de montaña (García Ruiz, 1988 y 1990; Lasanta Martínez, 1990a y 1990b; Llorente Pinto, 2003), referencia más representativa de la transformación territorial integral que en sí mismos han conocido, presupone apoyarnos en un conjunto de reflexiones que, a modo de hipótesis de trabajo y de formulaciones propositivas de análisis, sirvan como contexto teórico y práctico de referencia fundamental y como cuestiones centrales para el planteamiento de un posible debate al respecto. Y todo ello tomando como núcleo argumental que el modelo de organización y explotación del espacio y de estructuración del territorio de estas comarcas del sector central de la Cordillera Cantábrica que nos sirven como estudio de caso, han conocido procesos de transformación de distinta envergadura que han contribuido a cambiar, de modo muy desigual, la funcionalidad y orientaciones a las que antes se hizo mención, aunque sin desnaturalizar el perfil más tradicionalmente rural que las caracteriza (Ortega Valcárcel, 1999; Sumpsi Viñas, 1994).

a) La primera de estas proposiciones es la que nos hace afirmar que hoy conviven actores locales tradicionales (campesinado y sociedades rurales de mon- 
taña) con nuevos protagonistas (grupos de acción local y distintos profesionales que forman parte de los mismos, gestores de planes y programas específicos de dinamización turística, etc.) que intervienen en los procesos e iniciativas de gestión y organización del espacio. Así pues, aunque coexistiendo, el centro de todos estos mecanismos y agentes de regulación y gestión del propio espacio se ha trasladado desde la perspectiva exclusivamente agrarizante y controlada por los propios habitantes de estos pueblos a un conglomerado más diversificado en sus actividades y fines (sobrepasando el ámbito puramente agrario y dirigiéndose a otras formas de utilización socioeconómica del medio -la "multifuncionalidad" de la que habla Alario Trigueros, 2002-, a otros medios e instrumentos -la gestión y tramitación de ayudas exteriores- y a otros destinatarios externos) y más plural en sus componentes. Sólo a título de ejemplo y sin exhaustividad alguna, las referencias recogidas en el cuadro 2 son altamente indicativas de las afirmaciones que hacemos.

b) Los principales cambios y las mutaciones de mayor alcance que, recientemente, han conocido estas comarcas montañosas han estado provocados tanto por el declive del modelo tradicional de explotación, como por la progresiva marginalización de estas zonas geográficas desfavorecidas y por el impacto de las nuevas políticas y programas desarrollados y promovidos desde y por diferentes instancias políticas y gubernativas (gobiernos autonómicos, gobierno nacional y Unión Europea). Las dos primeras razones van, en cierto modo, unidas, pues la segunda puede considerarse como una consecuencia o efecto "funcional" de la primera. La reestructuración y el cierre que han conocido las actividades extractivas e industriales ${ }^{3}$ (el complejo sidero-metalúrgico de Reinosa, la minería de Guardo y Barruelo -ver cuadro 3-, la industria química de Guardo -que perdió un $70 \%$ de su empleo en la década de los noventa-, las industrias de Mataporquera...), así como la reestructuración que ha experimentado la ganadería de producción lechera (más implantada en la vertiente cántabra que en la palentina), unidas a otras regulaciones, como las vividas por algunos subsectores industriales agroalimentarios (Aguilar de Campoo -y su especialización galletera ${ }^{4}$ liderada inicialmente por Fontaneda, luego vendida al grupo Nabisco y actualmente reconvertida en la empresa Horno de Aguilar, complementada, asimismo, por la empresa Gullón- ha sido su principal exponente), han contribuido a reforzar más aún el carácter marginal -en lo económico-productivo, en líneas generales- de una zona de montaña que ya de por sí había ido conociendo una progresiva periferización merced a sus dificultades de articulación territorial interna y externa. La tercera de las razones es la que ha contribuido a redefinir y redirigir la explotación y gestión del espacio montañés y sus recursos hacia nuevos derroteros, de entre los que el turismo, en sus diferentes variantes entre las que descuella el "rural" y el "natural", y sus subsectores dependientes (restauración, hostelería...), es el más sobresaliente. 
Cuadro 2. Nuevos agentes, nuevos actores y nuevas figuras en la gestión y organización del espacio montañés (1985-2006).

- Gerentes de los Programas Leader I, II, + e Interautonómico, así como Proder I y II, en ambas vertientes: Saja-Nansa (Leader I, II y +); Campoo-Los Valles (Leader II, + e interautonómico), Liébana (Proder I y II) y Montaña Palentina (Leader I, II, + e interautonómico): 12 programas en total.

- Gerentes de los Planes de Dinamización Turística en Campoo-Los Valles (Cantabria) y en la Montaña Palentina (Palencia): 2 programas.

- Gerente de la Agencia de Desarrollo del Alto Carrión y la Montaña Palentina (ACADE).

- Responsables de las Agencias de Desarrollo Local (ADL)(2 en Cantabria: la de Reserva del Saja y la de Reinosa).

- Jefes técnicos de las dos Secciones Agrarias Comarcales (SAC) de la Montaña Palentina: Saldaña (de la que depende el área de Guardo) y Cervera de Pisuerga (que abarca las áreas de Aguilar de Campoo y Cervera) y de las 4 Oficinas Comarcales de la Consejeria de Agricultura y Ganaderia de Cantabria (Potes, Reinosa, San Vicente de la Barquera y Los Corrales de Buelna).

- Jefes técnicos de cada una de las tres Unidades de Desarrollo Agrario (UDA) de la Montaña Palentina: Guardo, Cervera y Aguilar.

- Jefes técnicos de cada una de las tres Unidades Veterinarias (UV) de la Montaña Palentina (Guardo, Cervera y Aguilar) y de las seis del sur-suroeste de Cantabria (Potes, Rionansa, Cabezón de la Sal, Reinosa I, Reinosa II y Reinosa III): 9 UV.

- Responsables de las 3 Oficinas Comarcales de Medio Ambiente de la Montaña Palentina (Aguilar, Cervera y Guardo).

- Coordinadores de cada una de las áreas cubiertas por los Centros de Acción Social (CEAS).

- Directores de las Zonas Básicas de Salud (ZBS) de las comarcas montañosas del sur-suroeste de Cantabria (6 zonas: Campoo, Los Valles, Saja, Nansa, Liébana y Besaya) y de la Montaña Palentina ( 3 zonas: Guardo, Cervera y Aguilar).

- Directores de las 8 Escuelas-Taller (3 en Cantabria -la de Reinosa, la de la Mancomunidad del Saja y la de Potes- y 5 en Palencia -tres en Aguilar de Campoo, una en Barruelo y una en Guardo-) y de los 2 Talleres de Empleo (uno en Cantabria, el de Saja, y otro en Palencia -Aguilar de Campoo-).

- Directores del Parque Nacional de Picos de Europa (Cantabria) y de los Parques Naturales de SajaBesaya (Cantabria) y Fuentes Carrionas-Fuentecobre-Montaña Palentina: 3 espacios protegidos.

- Directores del Ecomuseo Saja-Nansa (Cantabria), del Centro de Interpretación del Rio Ebro (Fontibie, Cantabria), del Museo del Ferrocarril (Campoo-Los Valles, Cantabria), del Aula de la Naturaleza (Vallejo de Orbó, Palencia), del Museo del Románico (Aguilar de Campoo, Palencia) y del Centro de Interpretación de la Minería (Montaña Palentina).

- Presidentes de las 6 Mancomunidades existentes en la Montaña Palentina y de las 7 que hay en el sur-suroeste de Cantabria: 13 Mancomunidades.

Fuente: Elaboración propia a partir de la información obtenida en los distintos organismos y servicios de las Administraciones autonómicas de Cantabria y de Castilla y León.

c) De igual modo puede afirmarse que se ha experimentado una importante transformación territorial de este espacio de montaña desde una dimensión perceptual y del conocimiento. Se ha pasado de la montaña que era más ignorada y hasta desconocida durante un largo periodo de tiempo, y de más difícil accesibilidad y apertura, a una montaña mucho más conocida actualmente. Una constatación íntimamente ligada, parcialmente, a la tercera de las razones apuntadas en el párrafo anterior. 
Cuadro 3. Indicadores de la transformación experimentada por algunas formas de explotación del territorio en el sector central de la Montaña Cantábrica: el ejemplo de la minería en la Montaña Palentina.

\begin{tabular}{|l|c|c|c|c|c|c|c|c|}
\hline \multirow{2}{*}{$\begin{array}{c}\text { Cuencas } \\
\text { mineras }\end{array}$} & \multicolumn{2}{|c|}{ Inicios años 80} & \multicolumn{2}{c|}{1993} & \multicolumn{2}{c|}{1998} & \multicolumn{2}{c|}{$\begin{array}{c}\text { Balance final } \\
(80-98)\end{array}$} \\
\cline { 2 - 10 } & $\begin{array}{c}\text { Empres } \\
\left(\mathrm{n}^{\circ}\right)\end{array}$ & $\begin{array}{c}\text { Empleo } \\
\left(\mathrm{n}^{\circ}\right)\end{array}$ & $\begin{array}{c}\text { Empres. } \\
\left(\mathrm{n}^{\circ}\right)\end{array}$ & $\begin{array}{c}\text { Empleo } \\
\left(\mathrm{n}^{\circ}\right)\end{array}$ & $\begin{array}{c}\text { Empres. } \\
\left(\mathrm{n}^{\circ}\right)\end{array}$ & $\begin{array}{c}\text { Empleo } \\
\left(\mathrm{n}^{\circ}\right)\end{array}$ & $\begin{array}{c}\text { Empres. } \\
\left(\mathrm{n}^{\circ}\right)\end{array}$ & $\begin{array}{c}\text { Empleo } \\
\left(\mathrm{n}^{\circ}\right)\end{array}$ \\
\hline Guardo-Valderueda & 11 & 1.081 & 5 & 648 & 4 & 530 & -7 & -551 \\
\hline Barruelo-La Pernía & 7 & 468 & 3 & 268 & 3 & 186 & -4 & -282 \\
\hline TOTAL & 18 & 1.549 & 8 & 916 & 7 & 716 & -11 & -833 \\
\hline
\end{tabular}

Fuente: Alario (coord.), 1999, p. 158-160-163 y Montaña Palentina. Plan de Desarrollo Rural integral, 2000, p. 51.

d) Asimismo, y como efecto muy vinculado a las dos proposiciones precedentes, ha habido un destacado proceso de cambio de orientación y funcional desde unas comarcas de montaña más claramente agrarizantes y tradicionales a unos espacios de montaña más adecuados para el ocio, el recreo, el turismo y el reencuentro con los paisajes naturales y culturales heredados, aunque sin perder realmente la dominante rural que sigue marcando sus perfiles más evidentes.

e) A todas estas proposiciones más generales bien pudieran añadirse otras más concretas, como por ejemplo la evolución que han experimentado las unidades y estructuras de organización interna y articulación social del territorio o la sustancial reorientación económico-productiva que ha conocido la explotación ganadera. Y en ambas se refuerza la primera de las formulaciones que hacíamos explícita anteriormente (cuando afirmábamos que hoy conviven actores locales tradicionales con nuevos protagonistas y agentes que intervienen en los procesos e iniciativas de gestión y organización del espacio). Así, en el primer caso, frente al papel aglutinador de los valles que tradicionalmente regulaban las relaciones intramontañosas -y que era producto de las ancestrales formas y estructuras acuñadas por los propios "montañeses"- se ha ido consolidando la presencia de las mancomunidades, por ejemplo, como resultado de impulsos y propuestas formuladas y aplicadas desde fuera de la propia sociedad rural montañesa, pues son los cuadros técnicos y políticos provinciales y regionales que gestionan el territorio los responsables de la implantación de estas figuras.

E idéntica argumentación puede utilizarse para el segundo de los ejemplos señalados. El producto "Carne de Cervera", marca de garantía que surgió en 1996 y que está promocionada y gestionada por la Asociación CAMPA, es claramente significativo del proceso de transformación -aunque parcial porque el compromiso no alcanza a la totalidad de los ganaderos- experimentado por algunas actividades tradicionales en la ocupación y explotación del territorio montañés. Es éste un pro- 
ducto que gira en torno a la calidad de un recurso tradicional ligado a la aptitud y potencialidades que para la ganadería extensiva ofrece este espacio de montaña y sus pastos. La paulatina orientación cárnica de la producción ganadera ha ido sustituyendo a la producción láctea cada vez más reducida. En la Montaña Palentina en 1999 eran 301 las explotaciones de vacuno de carne frente a 165 con vacuno de leche (Alario (coord.), 1999). Con más notoriedad se ha materializado este proceso en las comarcas del sur-suroeste de Cantabria (Delgado Viñas, 1996), donde entre 1978 y 1994 las comarcas de Campoo y Cabuérniga-Tudanca vieron descender el número de vacas de ordeño en un 26,3\% la primera y en un $59,9 \%$ la segunda, mientras que La Liébana, por el contrario, consolidó esta orientación (incrementó su cabaña de ordeño en un 1,7\%). Sin embargo, las vacas de no ordeño crecieron en las dos primeras comarcas mencionadas un $77,7 \%$ y un $12,7 \%$ respectivamente, mientras que descendieron un $55,4 \%$ en La Liébana. Proceso reafirmado, asimismo, por otros autores (Corbera y González, 1998: 395), quienes ya a finales de los años noventa y respecto al ámbito regional de toda Cantabria, afirmaban de forma significativa que

"...el censo de ganado frisón está descendiendo de forma notable (ha perdido un 15,3\% entre 1989 y 1996, con lo que de suponer un 75,6\% del censo vacuno total ba pasado a tan sólo un 64,7\%), mientras se incrementa el ganado de orientación cárnica (principalmente limusina y charolesa) o mixta. Pero ademäs... resulta evidente que una buena parte de los municipios que incrementan su censo de ganado vacuno corresponden a las comarcas occidentales (principalmente a las comarcas de campoo y Cabuérniga)".

\section{Procesos de transformación del territorio montañés}

\subsection{Factores más relevantes en que se han apoyado}

Las políticas públicas, bien situadas en el contexto eurocomunitario o bien en el de la propia política territorial estatal y regional, son su principal referencia explicativa. De todas ellas, algunas son compartidas con otros espacios de actuación dentro del territorio europeo y de España. Entre éstas primeras han de ser mencionadas las ayudas directas proporcionadas por los distintos fondos estructurales y sus programas de aplicación (FEDER y FEOGA sobre todo), las nuevas directrices y orientaciones que para el mundo rural han ido difundiéndose desde Bruselas (cambios en la PAC e introducción de nuevas medidas complementarias o de acompañamiento, promoción de la diversificación económica, pluriactividad, impulso a nuevos programas de desarrollo rural y local como Leader I, II y $+^{5}$, Proder I y $\mathrm{II}^{6}$, etc.), los Planes de Dinamización Turística (dos de estas comarcas cantábricas -Campoo/Los Valles y la Montaña Palentina- son beneficiarias de esta figura), o los distintos Programas Nacionales de Infraestructuras y Regionales de Carreteras. 
Cuadro 4. Algunas ayudas a la minería en las cuencas de la Montaña Palentina.

\begin{tabular}{|c|c|}
\hline $\begin{array}{r}\text { AYUDAS A } \\
\text { (concedidas a entidades locales para re } \\
\text { mejora urbana -ab }\end{array}$ & $\begin{array}{l}\text { MINERO (1989-2001) } \\
\text { lel entorno -escombreras, balsas, cortas, etc-- y para } \\
\text {, saneamiento, asfaltado, etc.-) }\end{array}$ \\
\hline ANO & SUBVENCIÓN CONCEDIDA (miles de $€$ ) \\
\hline 1989 & $288.483,72$ \\
\hline 1990 & $322.219,06$ \\
\hline 1991 & $213.300,00$ \\
\hline 1992 & - \\
\hline 1993 & $561.941,77$ \\
\hline 1994 & $298.330,69$ \\
\hline 1995 & $223.598,34$ \\
\hline 1996 & $212.813,68$ \\
\hline 1997 & $192.000,00$ \\
\hline 1998 & $399.108,00$ \\
\hline 1999 & $303.600,00$ \\
\hline 2000 & $684.000,00$ \\
\hline 2001 & $703.200,00$ \\
\hline TOTAL 1989-2001 & $4.402 .595,20$ \\
\hline $\begin{array}{r}\text { PROYECTOS SUBVENCIONADOS PC } \\
\text { MINERÍA DEL CARBÓN Y DESARROI } \\
\text { (para proyectos destinados a infraes } \\
\text { equipamic }\end{array}$ & $\begin{array}{l}\text { ITUTO PARA LA REESTRUCTURACIÓN DE LA } \\
\text { JATTVO DE LAS COMARCAS MINERAS 1997-2000 } \\
\text { resarial y a satisfacción de necesidades sociales y } \\
\text { íticos o más diversos-) }\end{array}$ \\
\hline$\underline{\mathrm{ANOO}}$ & SUBVENCIÓN CONCEDIDA (miles de $€$ ) \\
\hline 1997 & $1.710 .812,87$ \\
\hline 1998 & $2.174 .795,39$ \\
\hline 1999 & $1.819 .741,20$ \\
\hline 2000 & $5.284 .225,82$ \\
\hline TOTAL & $10.989 .575,28$ \\
\hline
\end{tabular}

Fuente: Servicio de Industria de la Delegación Territorial de la Junta de Castilla y León en Palencia e Instituto para la Reestructuración de la Minería del Carbón y Desarrollo Alternativo de las Comarcas Mineras (Ministerio de Economía).

Pero otras políticas públicas son más específicas y de marcada "territorialidad" (dirigidas a a zonas de montaña, a zonas donde la minería tenía una destacada presencia productiva, etc.), aunque también aplicables a otras zonas del territorio español; es el caso de la aprobación, ya hace poco más de veinte años, de la Ley 25/1982 sobre agricultura de montaña a la que se vincularon tanto la formulación de Programas de Ordenación y Promoción precisos -y a la larga poco efectivos en estas comarcas de la montaña cantábrica- como el desarrollo de instrumentos y medidas específicos tipo "indemnizaciones compensatorias"; o el caso de planes y fondos ya más propios, como el de Reordenación de la Minería del Carbón y de Desarrollo Alternativo de las Comarcas Mineras (con incidencia en áreas de la Montaña Palentina) (cuadro 4), el impacto de la iniciativa comunitaria Rechar y de los fondos 
MINER, etc ${ }^{7}$. Todos ellos han sido los principales resortes instrumentales de los que se han valido las diferentes actuaciones responsables de la transformación territorial de estas comarcas de montaña.

\subsection{Retomando las proposiciones de análisis antes formuladas: ¿hacia dónde se han orientado fundamentalmente las transformaciones territoriales?}

a) No cabe duda de que dentro de las transformaciones experimentadas en estas comarcas una de las más relevantes es la que tiene que ver con el cambio de imagen. A ello, de forma muy resumida, han contribuido sobre todo tres razones. Por una parte, una notable mejora de su accesibilidad y su vertebración fisico-territorial. Ha de añadirse además, en esta misma línea, un cambio notorio que ya está produciéndose: el que va unido a la construcción de un nuevo eje como es la autovía CantabriaMeseta, que cruza el sector central de la Montaña Cantábrica por su borde oriental (valles de Iguña y Besaya en Cantabria y el Campoo palentino y cántabro), y está muy avanzada en la vertiente cantábrica (desde Aguilar de Campoo hasta Torrelavega). Además, a principios del año 2000 concluía la reforma del eje de articulación interna de la Montaña Palentina en sus sectores central y occidental: la denominada "ruta de los pantanos" (pues va bordeando los embalses de Ruesga o Cervera, de Camporredondo y de Compuerto), que conecta las comarcas de Guardo y de Cervera.

Una segunda razón que ha contribuido a cambiar y mejorar la imagen de ambas zonas de montaña tiene que ver con la nueva cultura del ocio y las nuevas demandas que en este sentido ban ido generando las sociedades urbanas (tanto de los principales centros urbanos de las dos provincias -las capitales provinciales- en que se encuentran estas comarcas, como las de otras ciudades mayores de la región o de regiones vecinas o próximas, sobre todo del País Vasco y de Madrid). La mayor accesibilidad de estas áreas ha repercutido en la creación de una cierta imagen específica y "atractiva" de la Montaña proyectada, a través de medios muy distintos, en segmentos y mercados urbanos y turísticos provinciales, regionales y nacionales. En las dos vertientes del sector central de esta montaña cantábrica, este "turismo rural, verde e interior" ha transformado este territorio convirtiéndolo, funcionalmente, en alternativa y complemento, al mismo tiempo, bien del turismo convencional de veraneo en el litoral (caso de las comarcas de Cantabria), bien de otras rutas más difundidas y consolidadas (el románico de la Montaña Palentina y el atractivo natural de la misma frente a rutas como la del Camino de Santiago). Y todo ello ha adoptado formas específicas de promoción y difusión, recogidas bien en los "slogans" con los que se ofrecen los atractivos y recursos de estas comarcas de montaña, bien en los lemas que han definido los objetivos centrales de los diferentes programas de desarrollo rural subvencionados por la UE: "Montaña Palentina: Quédate a vivir" (lema de Adempa para el Leadert que, finalmente, no consiguió), "Montaña Palentina: Una verdadera 
ascensión" (lema de Adri Montaña Palentina para el Leader+ 2000-2006 que se está gestionando actualmente), "País Románico" (el patrimonio como activo central que aglutina las iniciativas agrupadas en el Leader+ interautonómico de Cantabria, Burgos y Palencia), "Montaña Palentina: placeres de altura" (lema impulsado desde el Consorcio Turístico de la Montaña Palentina), "Turismo Rural en Saja-Nansa: tu refugio natural" o "Comarca de Saja-Nansa: auténtico museo ecológico".

Finalmente, es justo la creación de esta cierta "imagen de calidad" que identifica a estos espacios de montaña -y ésta es la tercera de las razones anunciadas- la que contribuye igualmente a explicar el cambio general de imagen de los mismos; esta "marca específica y de calidad" que vende paisaje, que vende territorio, responde, en buena medida, al impacto del uso de nuevas tecnologias en la difusión y promoción de estas zonas, sobre todo en la segunda parte de los años noventa. Se ha pasado del folleto turístico y la propaganda sobre el papel, a la difusión en la red. Una nueva transformación de este territorio de montaña que se integra en nuevas redes de comunicación, intercambio y difusión y rompe con el carácter de territorio replegado sobre sí mismo y más aislado. La multiplicación de direcciones electrónicas, a través de las cuales la difusión y "venta" al exterior de los activos del territorio y de sus paisajes es infinitamente mayor a la conseguida por los medio más convencionales, se ha producido en un breve plazo de tiempo muy reciente, no superior a los ocho o diez últimos años: todas las comarcas tienen su página web, también casi todos los pueblos que la forman y además se integran en otras redes promovidas desde las instituciones provinciales o desde asociaciones específicas (promotoras de turismo rural, centrales de reservas, etc.).

b) Una segunda manifestación de la transformación experimentada por estos espacios de montaña en los quince últimos años ha sido la de la una paulatina implantación, en su evolución económico-productiva, de una creciente y marcada terciarización (cuadro 5). Apoyada, tal y como antes recordamos, en las nuevas recomendaciones introducidas desde el ámbito eurocomunitario (la diversificación y la pluriactividad como referencias centrales) y en los fondos habilitados para ello, se ha ido subrayando una cierta intensificación de la actividad económica no agraria. Y dentro de ella, ha sido el turismo rural la actividad hacia la que tanto el Leader I y II como el Proder, del que se han beneficiado, orientaron más fondos $(6,5$ millones de euros en la Montaña Palentina entre 1989 y 1999). Una actividad, la turística, que no es nueva en estas comarcas; pero sí lo es, sin embargo, el modelo en que quiere sustentarse: un turismo "rural, interior y sostenible" que aprovecha los recursos locales (patrimonio arquitectónico, caserío rural rehabilitado, itinerarios y rutas temáticos e históricos, productos gastronómicos y de artesanía propios de la zona y, sobre todo, el paisaje, principal activo). De su progresiva consolidación y desarrollo dan buena y detallada muestra recientes investigaciones llevadas a cabo (Aguña Aguerri, 2001, 2002 y 2003), quien a este respecto afirma significativamente, para el caso de la Montaña Palentina, que "al hilo de esta nueva tendencia, y en un 
intento de buisqueda de recursos alternativos a los tradicionales, se produce un "redescubrimiento" del territorio y del patrimonio natural e bistórico-artístico de esta comarca, a los cuales se les dota de un nuevo significado: no se trata ya de únicamente meros elementos de disfrute estético y recreativo, sino que se convierten en agentes clave de desarrollo, en cuanto que existan entidades gestoras y promotoras que sepan aprovecharlos" (Aguña Aguerri, 2002).

Cuadro 5. Creciente terciarización en la explotación del territorio montañés: su seguimiento a través de la evolución del IAE (1990-2000).

\begin{tabular}{|c|c|c|c|c|c|c|}
\hline \multirow{3}{*}{$\begin{array}{l}\text { Subsectores de Actividad } \\
\text { y } \\
\text { Epígrafes }\end{array}$} & \multicolumn{4}{|c|}{$\begin{array}{l}\% \text { / total registros de actividad de la } \\
\text { Montaña Palentina y de las comarcas } \\
\text { meridionales de Cantabria }\end{array}$} & \multicolumn{2}{|c|}{ Evolución (\%) } \\
\hline & \multicolumn{2}{|c|}{ Cantabria } & \multicolumn{2}{|c|}{ Palencia } & \multirow{2}{*}{$\begin{array}{c}\text { Cant. } \\
1992-99\end{array}$} & \multirow{2}{*}{$\begin{array}{l}\text { Palenc. } \\
1990-00 \\
\end{array}$} \\
\hline & 1992 & 1999 & 1990 & 2000 & & \\
\hline SUBSECTOR CONSTRUCCION & 14.1 & 16.8 & 11.2 & 17.7 & 1.42 .0 & +41.0 \\
\hline SUBSECTOR COMERCIAL & 57.3 & 57.1 & 44.5 & 52.5 & +18.3 & +6.0 \\
\hline Comercio mayorista & 4.3 & 3.1 & 4.2 & 2.7 & -14.5 & -42.1 \\
\hline Comercio minorista & 30.7 & 28.2 & 26.0 & 30.4 & -9.1 & +4.7 \\
\hline Intermediarios & 0.1 & 0.1 & - & 0.1 & - & - \\
\hline Restaurantes, cafeterías, bares & 16.5 & 17.8 & 10.0 & 13.6 & +42.6 & +22.3 \\
\hline Hospedaje & 3.1 & 5.7 & 1.1 & 2.7 & +119.1 & +112.5 \\
\hline Reparaciones & 2.6 & 2.2 & 3.2 & 2.8 & - & -19.5 \\
\hline $\begin{array}{l}\text { SUBSECTOR TRANSPORTES- } \\
\text { COMUNICACIÓN }\end{array}$ & 11.2 & 8.3 & 31.6 & 9.4 & -12.3 & -73.4 \\
\hline $\begin{array}{l}\text { SUBSECTOR INSTITUCIONES } \\
\text { FINANCIERAS, SEGUROS... }\end{array}$ & 2.8 & 3.4 & 1.6 & 5.4 & +45.9 & +200.0 \\
\hline SUBSECTOR SERVICIOS VARIOS & 6.01 & 6.6 & 4.1 & 7.3 & +31.8 & +58.4 \\
\hline
\end{tabular}

Fuente: IAE 1990 y 2000 (Cámara Oficial de Comercio e Industria de Palencia) y 1992 y 1999 (en el caso de la Cámara Oficial de Comercio, Industria y Navegación de Cantabria) y elaboración propia.

¿Cuáles han sido los resultados más evidentes del cambio que han conocido ambos espacios de montaña como consecuencia de la promoción de esta nueva forma de explotación?: fundamentalmente la de crear una infraestructura de alojamientos y de restauración al servicio del turismo rural (cuadro 6) inexistente en las dos comarcas a principios de los años ochenta, que se ha apoyado, además, en las ayudas recibidas para la rehabilitación y adaptación del caserío montañés a los distintos tipos de casas rurales y centros de turismo rural; se han generado morfologías diversas y tiplogías variadas de alojamientos que conviven con el caserío tradicional ${ }^{8}$.

De los efectos complementarios o derivados generados por el turismo rural ${ }^{9}$, uno de los que más sobresalen, por su impacto visual y su mejora de la trama del poblamiento 
y de la imagen de conjunto de los pueblos de estas áreas de montaña adecuados a estos usos (bien para Casas de Turismo Rural en sus distintas modalidades, bien para Centros de Interpretación al servicio de los visitantes, bien para los nuevos locales habilitados como restaurantes o mesones, etc.), es la rehabilitación del caserío y la recuperación del patrimonio arquitectónico, histórico, artístico, pero también de las infraestructuras que se crearon para otras actividades productivas ya hoy prácticamente desaparecidas, como la minería, generando iniciativas innovadoras ${ }^{10}$.

Cuadro 6. Efectos creados por el turismo rural sobre la infraestructura de alojamientos.

MONTAÑA PALENTINA:
$\begin{array}{r}\text { Año 1993: } 15 \text { alojamientos de turismo rural (creados por Leader I) } \\ \begin{array}{r}\text { Año 2000: } \\ 63 \text { (equivalentes al 58,3\% de toda la oferta turística de la zona, equidistribuidos } \\ \text { en } 18 \text { de los } 21 \text { municipios de la Montaña y con una capacidad de } 887 \text { plazas } \\ -47,7 \% \text { del total de plazas, excluidas las de "camping"-) }\end{array} \\ \text { COMARCAS DEL SUR-SUROESTE DE CANTABRIA: } \\ \text { Año 1992: } 4 \text { alojamientos "extrahoteleros" (concentrados en dos municipios de La Liébana: } \\ \text { Cabezón de Liébana y Camaleño) } \\ \text { Año 1999: } 63 \text { (distribudios entre } 19 \text { municipios, con especial importancia en La Liébana y en } \\ \text { Tudanca) }\end{array}$

Fuente: Delgado Viñas, Gil de Arriba, Hortelano Minguez y Plaza Gutiérrez; 2002.

c) Igualmente las transformaciones que han experimentado estas comarcas de montaña se refieren a los cambios desarrollados, en los últimos veinte años, en las figuras e instrumentos de estructuración social, funcional y administrativa del territorio. Se han generado nuevas estructuras y tipos de articulación administrativa como consecuencia tanto de la descentralización administrativa -producto de que progresivamente han asumido nuevas competencias los respectivos gobiernos autónomos- como de un notorio cambio experimentado en el nivel de dotación y prestación de servicios y equipamientos públicos (sanitarios, educativos, sociales, etc.), produciéndose igualmente estructuras mancomunadas de gestión.

Y así, a las viejas formas de estructuración y gobierno local del espacio montañés, de las que algunas perviven (en la Montaña Palentina, a escala municipal, se distinguen dos "centros" de poder local: el Ayuntamiento y la Junta Vecinal), se han superpuesto tipos nuevos generando distintos "mapas" de división territorial administrativa según los criterios utilizados ${ }^{11}$, que en más de una ocasión se solapan (mapas 2 y 3). Pero de entre todas ellas la que quizá mejor represente el cambio respecto a las viejas formas de articulación sean las "mancomunidades". Ello responde a que son fórmulas diseñadas para la aplicación de políticas de carácter supramunicipal (agrupan 
varios municipios) y también para el fomento de la cooperación que, si bien casi todas ellas se han creado para facilitar la prestación colectiva de ciertos servicios y atenciones básicas a todos los pueblos (recogida de basuras, de residuos sólidos urbanos, de abastecimiento y gestión del agua), en los Estatutos de muchas de ellas se recogen de forma explícita competencias orientadas al desarrollo económico y social ${ }^{12}$. Un total de 13 mancomunidades se extienden por este sector central montañés: siete en la vertiente cántabra y seis en la palentina, afectando a 19 municipios en aquélla (algo más de la mitad) y a otros 19 (la práctica totalidad) en ésta última.

$\mathrm{Y}$ junto a estas figuras se han puesto en marcha iniciativas, desconocidas hasta entonces en estas áreas, dirigidas a la formación y promoción del empleo y de actividades específicas para la población joven (Escuelas-Taller, Talleres de Empleo, Casas de Oficios); instrumentos, en definitiva, dirigidos a la actuación en grupos de población muy concretos de estas sociedades rurales de montaña. Se ha pasado, de este modo, de una carencia en equipamientos y servicios formativos a una presencia diversificada y orientada de los mismos, actuando tales iniciativas como instrumentos que quieren facilitar la estructuración y articulación social

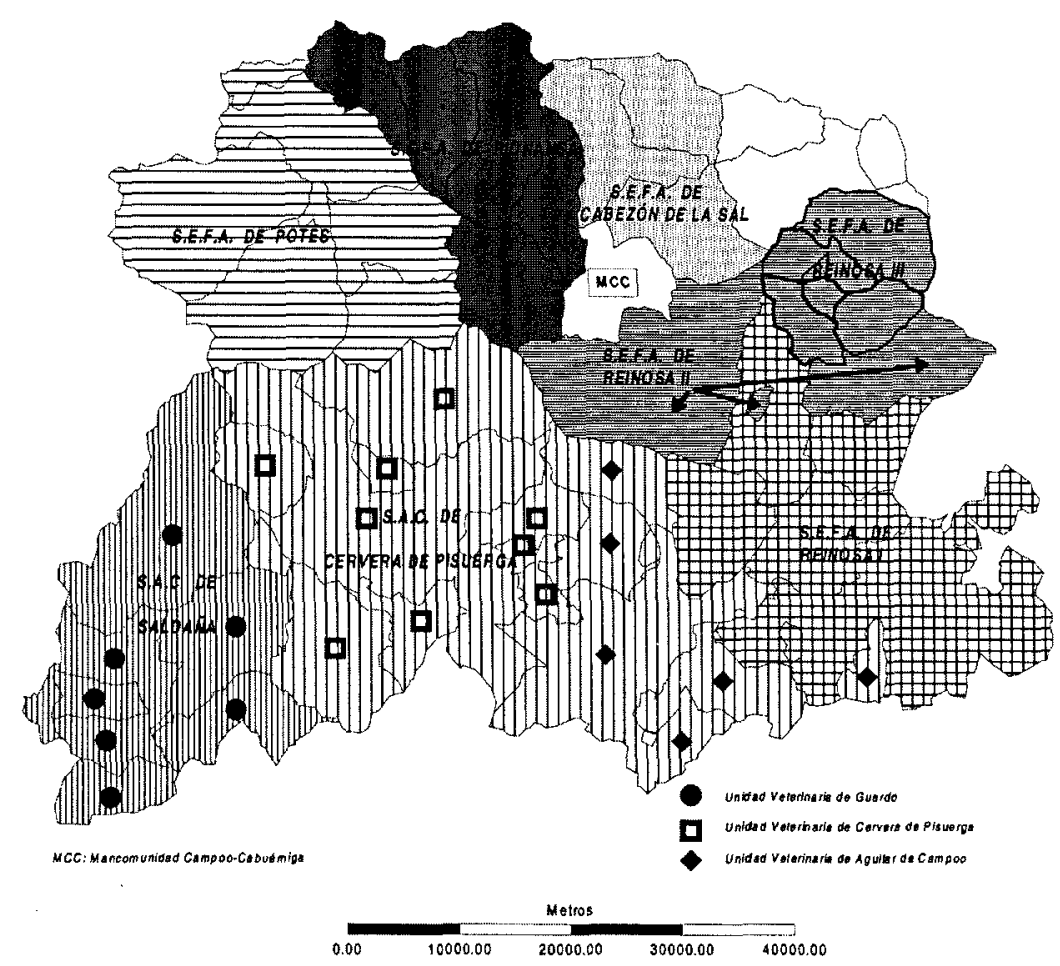

Mapa 2. Secciones agrarias comarcales (SAC) y unidades veterinarias (UV) en la montaña cantábrica. 


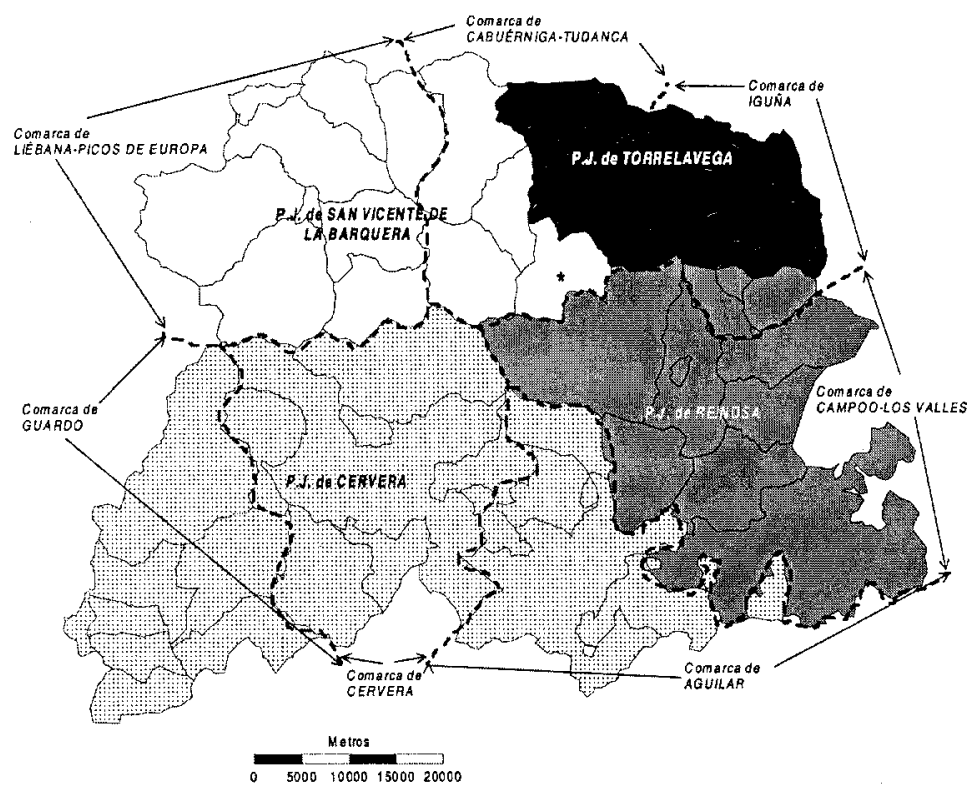

Mapa 3.

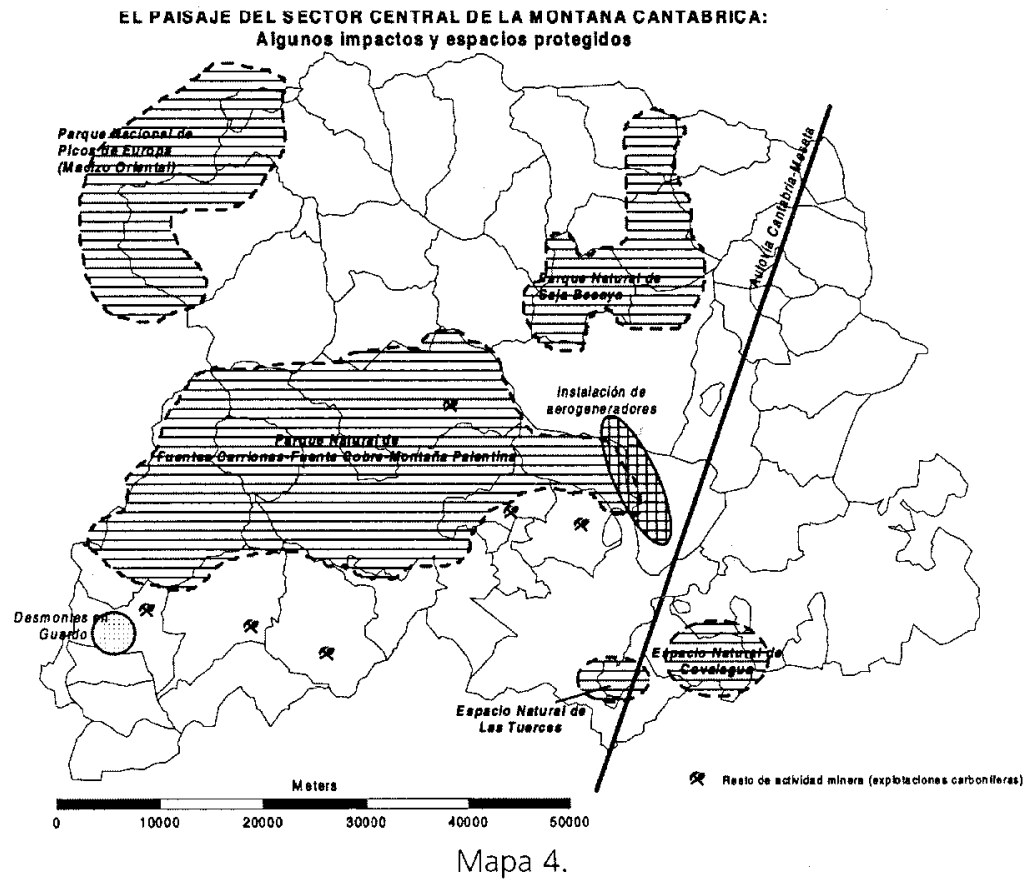


d) Finalmente, se han producido cambios importantes en el paisaje (mapa 4). Por un lado transformaciones sustanciales de su morfología; por ejemplo las explotaciones a cielo abierto realizadas en el municipio palentino de Guardo, con los consiguientes desmontes que han alcanzado a importantes masas forestales (el monte de Corcos es el caso más significativo); o los profundos "desventramientos" de parte de la montaña como consecuencia del trazado de la autovía Cantabria-Meseta en los altos valles de la montaña del sur de Cantabria (sur de Campoo y el encajado valle del río Besaya); o la instalación de nuevas formas de producción de energía más limpias, como la eólica, con la implantación de aerogeneradores en la subcomarca palentina de La Braña (Barruelo-Brañosera), en el límite oriental del Parque Natural de Fuentes Carrionas-Fuentecobre. Pero también se ha pasado de unos paisajes de montaña poco o nada protegidos o sometidos a regulación y carentes de plan y figura alguna de ordenación y protección (hasta mediados de los años ochenta sólo existían las Reservas de Caza del Saja, en Cantabria, y de Fuentes Carrionas, en la Montaña Palentina), a los nuevos Parques Naturales de Fuentes Carrionas y Fuente Cobre-Montaña Palentina (integrado en la Red de Espacios Naturales -REN- de Castilla y León, con algo más de 70.000 has. y disponiendo ya de un Plan de Ordenación de Recursos Naturales regulador de usos y aprovechamientos) y del Saja-Besaya (extendido por 24.500 has. y 6 municipios de los altos valles homónimos de la montaña de Cantabria), a los monumentos naturales de Covalagua y Las Tuerces en el municipio de Aguilar de Campoo y a la reclasificación y ampliación del Parque Nacional de los Picos de Europa.

\section{Notas}

* Esta contribución expone, parcialmente, resultados de los Proyectos de Investigación BSO2000-1421C02-01, BSO2000-1421-C02-02 y SA062/01 financiados, los dos primeros, por el Ministerio de Educación y Cultura -Secretaría de Estado de Educación, Universidades, Investigación y Desarrollo (Plan I+D+I 20002003) - y el tercero por la Consejería de Educación y Cultura de la Junta de Castilla y León (Programa de Apoyo a Proyectos de Investigación).

1 Las relaciones intercomarcales entre la Liébana (Cantabria) y la Montaña Palentina fueron más numerosas en el pasado por su común pertenencia a una misma unidad de organización histórica del territorio montañés, perfectamente individualizada en la Alta Edad Media: la Merindad de Liébana y Pernía, en la que se integraban casi todos los pueblos de la Liébana y los de la zona central de la Montana Palentina, pues los de la zona occidental (actual subcomarca de Guardo) pertenecían a la antigua Merinclad de Saldaña y los de la zona oriental a la Merindad de Aguilar de Campoo (Sánchez Albornoz, 1965: 159-179). Piénsese, a este respecto, que estas comarcas montañosas constituyeron los primeros espacios organizados y administrativamente definidos como consecuencia de la repoblación emprendida desde aquí en los siglos VII y VIII -la primera Carta-puebla datada en España es la de Brañosera, de la primera parte del siglo IX, año 824- y dirigida hacia el sur, hacia el valle del Duero. Algunas de sus figuras de estructuración social y espacial, como los valles, aparecen ya identificadas en los documentos altomedievales y han pervivido hasta tiempos actuales, si bien reformadas: Valle de Polaciones, Valle de Camargo, Valle de Cayón, Val de Baró, Valle de Cereceda, etc. (García de Cortazar, 1985, 1988 y 1999; García de Cortázar y Díez Herrera, 1982; Díez Herrera, 1990 y 1993). Por otro lado, muchas de las entidades de población que construyen la trama de este poblamiento montañés muy disperso son asentamientos que hunden, igualmente, sus raíces 
en época tan pretérita: es el caso de las "polas" asturianas y del norte de León, por ejemplo (Pola de Laviana, Pola de Lena, Pola de Gordón) (Ruiz de la Peña, 1981), o sus derivados como el cle "puebla" (Puebla de Lillo). En último término, también los monasterios que se asentaron tan tempranamente -con la repoblación- en estas comarcas extendieron su dominio (los "dominios" eclesiásticos) y desarrollaron una primitiva capacidad de organización funcional de este territorio (por ejemplo el de Piasca, en la Liébana cántabra; Montenegro, 1993). Incluso los monarcas otorgaron en señorio parte de este espacio montañés en el siglo XIII al Obispado de Palencia, que detentó la propiedad y título del Condado de La Pernía durante largo tiempo (Pérez Mier, 1934: 161-213).

2 Es un espacio de montaña (Ribas de Pina, 1948) cuyas altitudes oscilan entre los 2.000 y los $2.700 \mathrm{~m}$; las cotas más altas -situadas en el lado de Cantabria, en torno a los macizos occidental, central y oriental de los Picos de Europa, entre León y Cantabria y muy próximos al límite con la Montaña Palentina- sobrepasan los $2.600 \mathrm{~m}$. En la Montaña Palentina los picos Curavacas (2.525 m.) y Espigüete ( $2.450 \mathrm{~m}$.) son sus cumbres más importantes, situados en el norte, mientras que descienden hacia el centro (montaña media) y el sur (piedemonte y enlace con los páramos de raña).

3 Pese a todo, en la Montaña Palentina, por ejemplo, en el umbral del año 2000, aún mantenían una representatividad que, si bien distaba mucho de la que alcanzó en sus momentos más álgidos, todavía reunía un cierto volumen significativo. Así, y apoyándonos en la información proporcionada por el estudio coordinado por Alario (1999), en Velilla del Río Carrión, el 90\% de los asalariados industriales se concentraba en el sector de producción de energía eléctrica; la minería del carbón seguía polarizando, asimismo, empleo: el $70 \%$ del empleo industrial del municipio de Guardo, el $82 \%$ de los activos industriales en Barruelo de Santullán y el 68\% en Santibáñez de la Peña.

4. En Aguilar de Campoo (Alario (coord.), 1999) se concentraba a finales de los años noventa el $88 \%$ del empleo total de la industria alimentaria de la Montaña Palentina; y, más concretamente, la fabricación de galletas representaba el $77 \%$ de las actividades fabriles municipales y reunía al $95 \%$ de los activos ocupados en la industria alimentaria. Pero desde principios de los años ochenta hasta los primeros del siglo XXI el empleo "galletero" descendió un 63\%, reduciéndose, igualmente, el número de fábricas y empresas, cuyas representantes actuales se reducen a Gullón y Horno de Aguilar, las dos mencionadas en el texto.

5 Del Leader I (1989-93) y II (1994-99) han sido beneficiarias las comarcas Montaña Palentina y SajaNansa (Cantabria); Campoo-Los Valles lo fue sólo del Leader II; de Leadert (2000-2006) lo son, actualmente, Saja-Nansa, la parte central y occidental de la Montaña Palentina, y una parte de Campoo-Los Valles. Y del Leader + interautonómico "País Románico" lo son los municipios del sector oriental de la Montaña Palentina y los municipios meridionales de Campoo-Los Valles junto con uno (Rebolledo de la Torre) de la provincia de Burgos.

6 Sólo la comarca de Liébana, en esta zona central de la Montaña Cantábrica, se ha beneficiado del Proder I (1994-99) y también del Prodercan (2000-2006).

7 Según la información publicada en el periódico local-provincial Diario Palentino el 2 de enero de 2004 (p. 28) y facilitada por los sindicatos minero, el Plan del Carbón 2003 dejó en los dos tipos de municipios de actuación de la Montaña Palentina (municipios mineros -Barnelo de Santullán, la Pernía, Santibáñez de la Peña y Velilla del Río Carrión- y municipios "Rechar" -Cervera de Pisuerga y Salinas de Pisuerga-) cerca de quince millones de euros (exactamente 14.821,30€).

8 Teniendo en cuenta todas las tipologías de alojamiento, en Cantabria son los municipios lebaniegos quienes mayor número de actividades de alojamiento turístico concentran a finales de la década (Camaleno y Potes son los más representativos), mientras que en la Montaña Palentina es la comarca de Aguilar quien concentra poco más de la tercera parte de todas las licencias de hospedaje, si bien es la de Cervera la que sobresale por su especialización progresiva en estas actividades, siendo Cervera de Pisuerga y La Pernía los municipios que han incrementado de forma mâs destacada su número de licencias $(+266,6 \%$ y $+200 \%$ respectivamente entre 1990 y 2000). Estas tipologías de alojamiento turístico rural, por otro lado, difieren en una y otra de las Comunidades Autónomas (Cantabria y Castilla y León) por las que se extiende este espa- 
cio de montaña. En Cantabria se distinguen cuatro: Palacios y Casonas -2 en esta zona de montaña del sur de la región-; Posadas -40-; Viviendas rurales -43-; Casas de labranza -4; mientras que del lado castellanoleonés son cinco: Casas rurales de alquiler completo -47 en la Montaña Palentina-; Casas rurales de alojamiento compartido -6-; Centros de Turismo rural -8-; Posadas de Turismo rural -4-; Apartamento rural -7-.

9 Se ha producido un crecimiento generalizado, en todos los municipios, de las licencias de actividades de los subsectores "terciarios", tal y como se deduce del análisis del Impuesto de Actividades Económicas (IAE) en ambas vertientes (ver cuadro 5 del texto). Más concretamente, las referidas a "hospedaje" han crecido un 119,1\% entre 1992-1999 en los municipios montañosos de Cantabria y un 112,5\% entre 1990-2000 en los de la Montaña Palentina.

10 Es el caso del denominado "ciclo-raíl" en la Montaña Palentina, producto del Leader I, que ha explotado para fines turísticos 11 kilómetros (que discurren por los municipios de San Cebrián de Mudá y Salinás de Pisuerga) del ramal vinculado a la cuenca hullera de Barruelo (zona este de la Montaña) y a la línea de vía estrecha Bilbao-La Robla. Igualmente son representativos los "ciclo-raíles" de Las Rozas-Los Carabeos (de poco más de $30 \mathrm{kms}$ ) o Las Rozas-Bimón (de $10 \mathrm{kms}$ ), ambos en la conarca cántabra de Campoo-Los Valles y también promocionados por el grupo de acción local que coordinó el programa Leader.

11 Así, la división interna del territorio será diferente según se trate de "Zonas Básicas de Salud" (servicios sanitarios), zonas abarcadas por los distintos "Centros de Acción Social" (servicios sociales), de la comarcalización educativa (zonas de atracción de los distintos centros y niveles educativos: "Centros Rurales Agrupados", por ejemplo, áreas cubiertas por los distintos "Centros Públicos de Educación Infantil y Primaria"), de la comarcalización para los servicios agrarios (aparecen las "Secciones Agrarias Comarcales" - "Oficinas Comarcales" en Cantabria-, las "Unidades Veterinarias" -que constituyen una subdivisión de las anteriores- y las "Unidades de Desarrollo Agrario"), de los territorios abarcados por los distintos grupos de acción local que gestionan programas de desarrollo rural (territorios Leader y Proder en sus distintas fases), de la comarcalización ambiental en la vertiente cántabra ("Oficinas Comarcales" de la Consejería de Medio Ambiente), de los "Partidos Judiciales" o de las "Mancomunidades".

12 Un ejemplo muy ilustrativo a este respecto es el que proporciona la comarca cántabra de CabuérnigaTudanca. De las 7 mancomunidades en las que está presente, en dos de ellas (Mancomunidad CampooCabuérniga y Asociación y Comunidad de Campoo-Cabuérniga) lo hace junto con una parte de la comarca de Campoo-Los Valles. En otros dos casos (Mancomunidad de servicios de los Valles del Saja y Corona y Mancomunidad de Ayuntamientos "Reserva del Saja") desborda sus límites hacia el norte, fuera de la zona de montaña, hacia Cabezón de la Sal y Mazcuerras. Finalmente, en otra de más amplio radio, la Mancomunidad Saja-Nansa, que gestiona los programas Leadert, Equal e Interreg III, figura junto con municipios de La Liébana y con otros de la zona noroeste de cantabria y hasta con municipios de la costa occidental de la región (caso de San Vicente de la Barquera, de Val de San Vicente y de Valdáliga). También desborda hacia el noroeste y hacia la costa en el caso del espacio geográfico ocupado por los municipios de la comarca beneficiados en su momento por los programas Leader I y II (Leader "Saja-Nansa").

\section{Bibliografía}

Aguña Aguerri, I. (2001): El desarrollo turistico de la Montaña Palentina. Diputación Provincial de Palencia. 231 pp.

Aguña Aguerri, I. (2002): La larga trayectoria del desarrollo turístico en la Montaña
Palentina. En Cuadernos de Turismo, $\mathrm{n}^{\circ}$ 10, Murcia, p. 123-136.

Aguña Aguerri, 1. (2003): Promoción y comercialización de la actividad turística en la Montaña Palentina. En Santos Solla, X. (ed.): 
La Geografia y la gestion del turismo. Actas VIII Coloquio de Geografia del turismo, ocio y recreación. Universidade de Santiago de Compostela, Publicacións, p. 67-74.

Alario Trigueros, M. (coord.) (1999): Estudio sobre la situación económica y social de la Montaña Palentina. Departamento de Geografía de la Universidad de Valladolid y Junta de Castilla y León, 279 pp.

Alario Trigueros, M. (2002): La Montaña Palentina: entre la crisis y la multifuncionalidad. En Medio Ambiente en Castilla y León, $\mathrm{n}^{\circ}$ 18. Consejería de Medio Ambiente y Ordenación del Territorio, Junta de Castilla y León. Valladolid, p. 19-35.

Calderón Calderón, B. (1996): La organización tradicional del espacio en Campóo. Economía y sociedad en un valle de montaña de la Cordillera Cantábrica. Ed. Comité Organizador del Festival Cabuérniga-Música de los Pueblos del Norte; Revista Cantárida, Músicos Populares Independientes "NOS" y Amigos del Festival; Santander; 120 pp.

Corbera Millán, M. (ed.) (1999): Cambios en los espacios rurales cantábricos tras la integración de España en la Unión Europea. Santander, Universidad de Cantabria.

Corbera Millán, M., González Pellejero, R. (1998): Revalorización de una comunidad de pastos en Cantabria: la Mancomunidad Campoo-Cabuérniga. En $I X$ Coloquio de Geografia Rural. Comunicaciones; Departamento de Geografía, Prehistoria y Arqueología de la Universidad del país Vasco-Grupo de Trabajo de Geografía Rural de la Asociación de Geógrafos Españoles, Vitoria, p. 395-402.

Delgado Viñas, C. (1996): Procesos actuales de reorganización del sistema productivo agrario en espacios rurales de la montaña cantábrica. En Actas del VIII Coloquio de Geografia Rural; Asociación de Geógrafos Españoles-Universidad de Zaragoza. Jaca, p. 97-108.

Delgado Viñas, C. (1997): Crisis y reconversión en espacios rurales de montaña en Cantabria. Ería, n 44 , p. 335-357.

Delgado Viñas, C. (1998): Cambios recientes en las orientaciones productivas de la ganadería bovina en Cantabria. En $I X$ Coloquio de Geografía Rural. Comunicaciones; Departamento de Geografía, Prehistoria y Arqueología de la Universidad del país Vasco-Grupo de Trabajo de Geografía Rural de la Asociación de Geógrafos Españoles, Vitoria, p. 403-412.

Delgado Viñas, C. (1999a): Avances y rémoras en el proceso de renovación de la explotación pecuaria en Cantabria. En Professor Joan Vilà $i$ Valentí. El seu mestratge en la Geografia Universitaria, Universidad de Barcelona, p. 875-889.

Delgado Viñas, C. (1999b): La urbanización del campo en Cantabria. En El territorio y su imagen. Asociación de Geógrafos Españoles-Universidad de Málaga, vol. II, p. 1011-1021.

Delgado Viñas, C. (2000): La diversificación espacial de la ganadería bovina en Cantabria. En Espacio natural y dinämicas territoriales (Homenaje al Dr. D. Jesís Garcia Fernández). Servicio de Publicaciones de la Universidad de Valladolid, p. 409-422.

Delgado Viñas, C., Fuente Royano, Ma.$T$. de la (2000): Las estrategias de desarrollo rural: una valoración del PRODER en Cantabria. En Ĺtos espacios nurales en el cambio de 
siglo: incertidumbres ante los procesos de globalización y desarrollo; Asociación de Geógrafos Españoles/Departamento de Geografía y Sociología de la Universidad de Lleida, Lleida, p. 723-734.

Delgado Viñas, C., Gil de Arriba, C., Hortelano Mínguez, L.A., Plaza Gutiérrez, J.I. (2002): Actividades y usos extraagrarios en el sector central de la Montaña Cantábrica. En Actas del XI Coloquio de Geografia Rural: Los espacios murales entre el boy y el mañana (Santander, 2002). Universidad de Cantabria, Santander, p. $569-580$.

Delgado Viñas, C., Gil de Arriba, C., Hortelano Mínguez, L.A., Plaza Gutiérrez, J.I. (2003a): La gestión turística de algunas comarcas de montaña cantábricas: una nueva imagen del territorio a partir de una utilización sostenible y de una oferta de calidad. En Santos Solla, X. (Ed.): La Geografía y la gestión del turismo. Actas VIII Coloquio de Geografía del turismo, ocio y recreación. Universidade de Santiago de Compostela. Publicacións, p. 223-236.

Delgado Viñas, C., Gil de Arriba, C., Hortelano Mínguez, L.A., Plaza Gutiérrez, J.I. (2003b): Turismo y desarrollo local en algunas comarcas de la Montaña Cantábrica: recursos y planificación. En Cuadernos de Turismo, $\mathrm{n}^{\circ} 12, \mathrm{p} .7-34$.

Delgado Viñas, C., Gil de Arriba, C., Hortelano Mínguez, L.A., Plaza Gutiérrez, J.I. (2003c): Perspectivas y valoración de la aplicación del Plan Especial de Áreas Periféricas de Castilla y León en la Montaña Cantábrica. En XXIX Reunión de Estudios Regionales: "Competitividad regional en la UE ampliada". Santander, 27 y 28 de noviembre de 2003, CD-Rom. Ed. Servicio de Publicaciones de la Universidad de Cantabria.
Delgado Viñas, C., Gil de Arriba, C., Hortelano Mínguez, L.A., Plaza Gutiérrez, J.I. (2003d): La nueva dinámica económica y territorial de los espacios rurales periféricos: el caso del sector central de la Montaña Cantábrica. En XXIX Reunión de Estudios Regionales: "Competitividad regional en la UE ampliada". Santander, 27 y 28 de noviembre de 2003, CD-Rom. Ed. Servicio de Publicaciones de la Universidad de Cantabria.

Delgado Viñas, C., Gil de Arriba, C., Hortelano Mínguez, L.A., Plaza Gutiérrez, J.I. (2004); La renovación rural en los espacios de montaña: las comarcas de la vertiente norte del sector central de la Cordillera Cantábrica. En Investigaciones Geográficas, n 33 (en prensa).

Díez Herrera, C. (1990): La formación de la sociedad feudal en Cantabria. La organización del territorio en los siglos $I X$ al XIV. Universidad de Cantabria y Asamblea Regional de Cantabria, Santander; 301 pp.

Díez Herrera, C. (1993): El "Valle", unidad de organización social del espacio en la Edad Media. En Estudos Medievais (Oporto), 10, p. 3-32.

Fuente Royano, $M^{a}$.T. de la, Delagado Viñas, C. (2000): Las diferentes formas de abordar el desarrollo rural desde el PRODER: los ejemplos de Cantabria. En Los espacios murales en el cambio de siglo: incertidumbres ante los procesos de globalización $y$ desarrollo. Asociación de Geógrafos Españoles/Departamento de Geografía y Sociología de la Universidad de Lleida, Lleida, pp. 650-662.

García de Cortázar, J.A. (coord.) (1985): Organización social del espacio en la España medieval. La Corona de Castilla en los siglos VIII a XV. Ariel, 248 pp. 
García de Cortázar, J.A. (1988): Organización social del espacio: propuestas de reflexión y análisis histórico de sus unidades en la España medieval.. En Studia Historica. Historia medieval, VI, p. 195-236.

García de Cortázar, J.A. (ed.) (1999): Del Cantábrico al Duero. Trece estudios sobre organización social del espacio en los siglos VIII a XIII. Universidad de Cantabria y Parlamento de Cantabria, Santander, 558 pp.

García de Cortázar, J.A., Díez Herrera, C. (1982): La formación de la sociedad bispano-cristiana del Cantábrico al Ebro en los siglos VIII a XI. Planteamiento de una bipótesis y análisis del caso de Liébana, Asturias de Santillana y Trasmiera. Ed. Estudio, Santander, 229 pp.

García Ruiz, J.Mª. (1988): La evolución de la agricultura de montaña y sus efectos sobre la dinámica del paisaje. En Revista de Estudios Agrosociales, n ${ }^{\circ}$ 146, p. 7-37.

García Ruiz, J.Ma (ed.) (1990): Geoecologia de las äreas de montaña. Geoforma Ediciones, Logroño, 337 pp.

Gil de Arriba, C. (1997a): Turismo rural y turismo activo en la Comunidad Autónoma de Castilla y León: la Montaña Palentina, un ejemplo a observar. En Valenzuela Rubio, M. (coord.): Los turismos de interior. El retorno de la tradición viajera. Madrid. Ediciones de la Universidad Autónoma de Madrid, p. 459-473.

Gil de Arriba, C. (1997b): Turismo rural y nuevas vías para un desarrollo sostenible en la Montaña Palentina. El reto de una aparente antinomia. En Homenaje a Luis Alfonso González Polledo. Secretariado de Publicaciones de la Universidad de León, p. $115-133$.
Gil de Arriba, C. (1998): Turismo rural en la Montaña Palentina, vías y orientaciones para un desarrollo local sostenible, Estudios Turísticos, 135, p. 51-66.

Gutiérrez González, S. (2000): Balance de la aplicación de la iniciativa europea de desarrollo rural Leader en Campoo (Cantabria). En Los espacios rurales en el cambio de siglo: incertidumbres ante los procesos de globalización y desarrollo. Asociación de Geógrafos Españoles/Departamento de Geografía y Sociología de la Universidad de Lleida, Lleida, p. 669-678.

Hortelano Mínguez, L.A., Plaza Gutiérrez, J.I. (2004a): Propuestas institucionales para fomentar el turismo en espacios naturales protegidos: valoración del "Programa Parques Naturales en Castilla y León" y su incidencia en la Montaña Palentina. En VIII Congreso de la Asociación Española de Expertos Cientificos en Turismo (AECIT): nuevos segmentos $y$ destinos turisticos. Asociación Española de Expertos Cientificos en Turismo (AECIT), (en prensa).

Hortelano Mínguez, L.A., Plaza Gutiérrez, J.I. (2004b): Valoración de algunas propuestas de desarrollo de un espacio rural de montaña a partir de la promoción de iniciativas turísticas singulares vinculadas al patrimonio minero. En VIII Congreso de la Asociación Española de Expertos Cientificos en Turismo (AECIT): nuevos segmentos y destinos turísticos. Asociación Española de Expertos Científicos en Turismo (AECIT), (en prensa).

Lasanta Martínez, T. (1990a): Tendences actuelles de l'organisation spatiale des montagnes espagnoles. Annales de Géographie, $\mathrm{n}^{\circ}$ 551, p. 51-71.

Lasanta Martínez, T. (1990b): Tendencias en el estudio de los cambios de uso del suelo 
en las montañas españolas. En Pirineos, $\mathrm{n}^{\circ} 135$, p. $73-106$.

Llorente Pinto, J.M. (2003): Bilan des transformations dans les zones de montagne espagnoles. En CERAMAC: Crises et mutations des agricultures de montagne. Presses Universitaires Blaise Pascal, Clermont-Ferrand, p. 675-690.

Montaña Palentina. Plan de Desarrollo Rural Integral: Montaña Palentina: "Un verdadero ascenso". Palencia, 2000. 2 vols. (vol. I: Información y diagnóstico; vol. II: Estrategia).

Montenegro, J. (1993): Santa María de Piasca. Estudio de un territorio a través de un centro monástico (857-1252), valladolid.

Montiel Molina, C. (2003): Tradición, renovación e innovación de los usos y aprovechamientos en las áreas rurales de montaña. En Cuadernos Geográficos, $\mathrm{n}^{\circ} 33$, Universidad de Granada, p. 7-26.

Ortega Valcárcel, J. (1987): La Cantabria rural: sobre "La Montaña". Servicio de Publicaciones de la Universidad de Cantabria, Santander, 90 pp.

Ortega Valcárcel, J. (1989): La economía de montaña, una economía de equilibrio, Eria, ${ }^{\circ} 19-20$, p. 115-128.

Ortega Valcárcel, J. (1999): Procesos de cambio en las áreas rurales cantábricas. La evolución de los espacios rurales cantábricos y la integración de España en la Unión Europea. En Corbera Millán, M. (ed.): Cambios en los espacios rurales cantábricos tras la integración de España en la Unión Europea. Santander, Universidad de Cantabria, p. 237-250.

Ortega Valcárcel, J. (2002): Áreas de montaña: de la supervivencia a la integración (texto de la conferencia inaugural pronunciada en las Jornadas sobre Patrimonio y desarrollo en áreas de montaña, organizadas por la Asociación de Geógrafos Españoles -AGE- y celebradas en Oviedo en noviembre de 2002) (texto policopiado).

Pérez Mier, L. (1934): El Condado de Pernía. En Semana "Pro Ecclesia et Patria". Conferencias. Palencia, p. 161-213.

Plaza Gutiérrez, J.I. (1989): El espacio geográfico de las zonas de montaña: variedad de situaciones, variedad conceptual y tardío y variado tratamiento. El ejemplo castellano-leonés. En XI Congreso Nacional de Geografia. Ponencias y Relatorias, vol. II, AGE/Universidad Complutense de Madrid, p. 218-227.

Plaza Gutiérrez, J.I. (1992): Un espacio rural contrastado: la Montaña Palentina. En Cabero Diéguez, V., Llorente Pinto, J.M., Plaza Gutiérrez, J.I. y Pol Méndez, C. (Eds.): El medio rural español. Cultura, paisaje y naturaleza. Ed. Universidad de Salamanca, Salamanca, vol. II; p. 783-791.

Plaza Gutiérrez, J.I. (1993): Desarrollo regional, medio ambiente y recursos naturales. Reflexiones teóricas, valoración integrada y ejemplificación en las áreas de montaña. El caso de la región montañosa de la Cordillera Cantábrica. En XVIII Reunión de Estudios Regionales, Toledo, Ed. Universidad de Castilla-La Mancha y Asociación Española de Ciencia Regional, p. 317-322.

Plaza Gutiérrez, J.I. (1994): Actividad agraria, valores ambientales y desarrollo rural en el espacio natural protegido de Fuentes Carrionas y Fuente Cobre (Montaña Palentina). En Asociación de Geógrafos Españoles-Grupo de Trabajo de Geografía Rural: Propiedad, actividad agraria $y$ 
medio ambiente en España y América Latina. Actas del VII Coloquio de Geografia Rural. Ponencias y excursiones; Servicio de Publicaciones de la Universidad de Córdoba, Serie "Estudios de Geografía" no 9, p. 430-434.

Plaza Gutiérrez, J.I. (1999): Reflexiones sobre la interdependencia entre formas de turismo y organización del espacio. El ejemplo de la Montaña Palentina. En El Territorio y su Imagen. Actas del XVI Congreso de Geógrafos Españoles, Volumen II. Málaga, Ed. Asociación de Geógrafos Españoles. Departamento de Geografía de la Universidad de Málaga, Málaga, p. 647-656.

Plaza Gutiérrez, f.I. (2000): Espacios naturales, territorio y desarrollo (reflexiones teóricas y sobre formas de gestión. Algunos ejemplos de la región castellano-leonesa). En Valle Buenestado, B. (coord.): Geografia y espacios protegidos; Asociación de Geógrafos Españoles y Federación de Espacios Naturales Protegidos de Andalucía (FENPA), Murcia, p. 311-332.
Plaza Gutiérrez, J.I. (2001): Contrastes comarcales en la Montaña Cantábrica. En Espacio natural y dinâmicas territoriales (Homenaje al Dr. D. Jesús Garcia Fernândez). Servicio de Publicaciones de la Universidad de Valladolid, p. 439-450.

Plaza Gutiérrez, J.I. (2002): Changéments récents dans les montagnes du Nord et Nord-Ouest de l'Espagne. En CERAMAC: Crises et mutations des agricultures de montagne. Presses Universitaires Blaise Pascal, Clermont-Ferrand, p. 659-674.

Ribas de Pina, M. (1948): La región natural llamada "La Montaña" (Estudio de Geografía Humana). En Boletin de la Real Sociedad Geográfica, tomo LXXXIV, p. 164-178.

Ruiz De la Peña, J.I. (1981): Las "polas" asturianas en la Edad Media, Oviedo.

Sánchez Albornoz, C. (1965): Estudios sobre las instituciones medievales españolas; Universidad Nacional Autónoma de México, Instituto de Investigaciones Históricas; México, 828 pp. 